\title{
発電式振動抑制装置に関する研究*
}

\author{
松岡太-*1, 砂子田 勝 昭*2 \\ 平元 和 彦*1, 大 竹 隆 文*3
}

\section{Study on Vibration Control Device Using Power Generator}

\author{
Taichi MATSUOKA*4, Katsuaki SUNAKODA, \\ Kazuhiko HIRAMOTO and Takafumi OHTAKE \\ ${ }^{* 4}$ Faculty of Engineering and Resource Science, Akita University, \\ 1-1 Tegata Gakuen-machi, Akita-shi, Akita, 010-8502 Japan
}

\begin{abstract}
In this paper, the authors developed a vibration control device (V.C.D.) using a power generator and a flywheel which is suitable for vibration suppression of a structure. The V.C.D. consists of a ball screw, a ball nut, a flywheel, a gear, and a power generator. The linear motion is converted into a rotating motion by the ball screw mechanism. The damping force is generated by the power generator, and controlled by an electric resistance at the terminal of the power generator. The inertial force is created by the flywheel which is attached to the end of the screw shaft. Since these forces are magnified by the ball screw and the gear, the V.C.D. has resisting force characteristics as the sum of the controllable damping force and the inertial force in the low frequency range. In order to investigate dynamic properties, a test V.C.D. is manufactured, and the resisting force characteristics are measured by using a vibration actuator. The experiments of frequency response are carried out using a shaking table, and the experimental results are compared with the theoretical results. The seismic responses are calculated under a semiactive control based on Linear Quadratic Regulator, and the effects of the vibration suppression of the V.C.D. are discussed experimentally and numerically.
\end{abstract}

Key Words: Vibration Control, Vibration Control Device, Damping, Damper, Semiactive Control, Power Generator, Ball Screw

\section{1. ま え がき}

近年, 地震時における構造物の長周期運動や大振幅 振動が重要視されつつある. それらの振動は, 時間に 対して緩やかに進行するため,これまで一般的に考え られていなかった，それらを対象にした振動抑制装置 は，あまり例がなく見受けられない。 また，人工衛星 などの宇宙構造物は剛性が小さく, これらの振動が悪 影響を及ぼすことが考えられる，構造物などの主振動 体と基礎との間に回転慣性体や振り子式質量を設置し たり, 流体の質量移動を利用する方法は, 古くから研 究されている(1)-(3). 一方, 川口らは配管の振動を抑制 するために, 回転慣性モーメントを利用したメカニカ ルスナッバを開発し(4), これまでに多くの研究が行わ れてきた ${ }^{(5)(8)}$. 最近では, 大亦らがボールねじを用い

* 原稿受付 2007 年 4 月 12 日

*1 正員, 秋田大学工学資源学部(业010-8502 秋田市手形学園 町 1-1).

*2 正員, フェロー, 秋由大学工学資源学部.

*3 KYB (株) (恶 105-6111 東京都港区浜松町 2-4-1).

E-mail : matsuoka@ipc.akita-u.ac.jp
慣性質量を利用したダンパの研究(9)(10), 古橋, 石丸ら が慣性接続質量による応答制御の研究(11)，および川股 らは流体質量を用いたダンパの研究を行っている ${ }^{(12)}$. 基礎免震において, 振動系の固有振動数は質量と剛性 に依存するため, 慣性接続質量を取付けることにより 見かけの質量が増加し，固有振動数が低くなるととも に，共振ピークも低減する.

著者らはこれまでに，流体の慣性質量効果を用いた 振動遮断装置を開発し，その流体慣性質量の効果を実 証した(13)(14). 本研究では, 構造物の制振を目的として, ボールねじを用いた減衰機構と慣性質量を併せ持つ発 電式振動抑制装置を開発した ${ }^{(15) \sim(17)}$. 本装置は, 発電 機によって減衰力を制御し, フライホイールによって 慣性力を発生させる．セミアクティブ型振動抑制装置 として機能するため, アクティブ型に比べて比較的安 価で, 安定性にも優れているといえる，本装置を設計 製作し，加振機を用いた抵抗力測定実験を行った。 そ の実験結果から理論の正当性を確かめた，次に，本装 置を一自由度振動モデルに取付けて, 周波数応答実験 を行い，本装置の振動抑制効果を検証した。また，地 
震時における制振効果を確かめるために，最適レギュ レータによるセミアクティブ制御手法を用いた一自由 度振動モデルの地震応答シミュレーションを行ったの で，その成果を示す.

\section{2. 発電式振動抑制装置の構造と抵抗力}

$2 \cdot 1$ 構造と仕組み＼cjkstart本報で提案する発電式振動 抑制装置の構造を図 1 に, 諸元を表 1 に示す. 本装置 は，ボールねじ，ボールナット，ピストン，ベアリン グ, カップリング, フライホイール, ギア, 発電機お よびロッドエンドから成る，ロッドエンド間の並進運 動は, ボールねじ機構によって回転運動に変換され, 増速ギアを介して発電機を駆動させる仕組みである. 発電機は内部コイルの印加電流の大きさによって回転 速度を制御できるので，その逆にコイルの電流すなわ ち発電機の両端子間の負荷抵抗を変えることによって 回転速度に比例した減衰力を発生させることができる. 両端子間には, 負荷抵抗の値を任意に変化させるため の電流制御器を接続する. また, フライホイールはボ 一ルねじ軸端に取付けられており，その回転慣性モー メントから大きな慣性力が得られる.

$2 \cdot 2$ 抵抗力特性落ールねじ軸端の回転角 $\theta_{1}$ と ロッドエンド間の相対変位 $u$ は幾何学的な関係から

$$
\theta_{1}=\frac{2 \pi}{L} u
$$

となる．ここで，L はボールねじのリードである．発 電機にはギアが取付けられているため, そのギアの増 速比を $\alpha$ とると発電機軸の回転数 $\dot{\theta}_{2}$ は次式となる.

$$
\dot{\theta}_{2}=\alpha \frac{2 \pi}{L} \dot{u}
$$

発電機に発生する誘導起電力 $E$ は発電機軸の回転数 $\dot{\theta}_{2}$ に比例するため, その比例定数を起電力定数 $K_{E}$ とし て表すと次式が得られる.

$$
E=K_{E} \dot{\theta}_{2}
$$

一方，発電機から発生する回転トルク $T$ は電機子電流 $I_{a}$ に比例するため, その比例定数をトルク定数 $K_{T}$ とし て表すと

$$
T=K_{T} I_{a}
$$

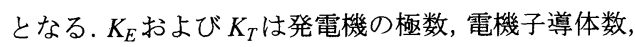
毎極磁束数，およびブラシ間の並列回路数によって定 まる定数である.

発電機には電機子の内部抵抗 $R_{a}$ が存在するため, オ 一ムの法則から電機子電流は次式となる.

$$
I_{a}=\frac{E}{R_{t}+R_{a}}
$$

ここで， $R_{t}$ は発電機の両端子間の負荷抵抗である.し たがって, 発電機で生じるトルク $T$ は式(2)〜(5)より次 式で与えられる.

$$
T=\frac{K_{E} K_{T}}{R_{t}+R_{a}} \dot{\theta}_{2}
$$

よって減衰力 $F_{D}$ は式(6)から

$$
F_{D}=\frac{1}{\eta}\left(\frac{2 \pi \alpha}{L}\right) T=\frac{1}{\eta}\left(\frac{2 \pi \alpha}{L}\right)^{2} \frac{K_{E} K_{T}}{R_{t}+R_{a}} \dot{u} \quad \cdots(7)
$$

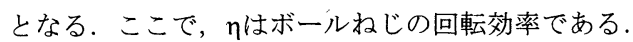
上式から，負荷抵抗がない短絡時 $\left(R_{t}=0\right)$ では減衰力 が最大限になり，負荷抵抗が無限大すなわち開放時 $\left(R_{t}\right.$

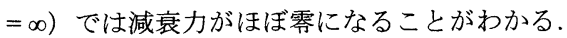

発電機内部の回転部品およびフライホイールによる 回転慣性モーメントによる慣性力 $F_{I}$ は次式で与えら れる.

$$
\begin{aligned}
F_{I}= & \frac{1}{\eta}\left(\frac{2 \pi}{L}\right)\left(J_{1} \frac{d^{2} \theta_{1}}{d t^{2}}+\alpha J_{2} \frac{d^{2} \theta_{2}}{d t^{2}}\right) \\
& \frac{1}{\eta}\left(\frac{2 \pi}{L}\right)^{2}\left(J_{1}+\alpha^{2} J_{2}\right) \ddot{u}
\end{aligned}
$$

ここで, $J_{1}, J_{2}$ は発電機内部の回転部品およびフライ ホイールの慣性モーメントを示す. したがって, 本ダ ンパの全抵抗力は式(7), (8)より次式で与えられる.

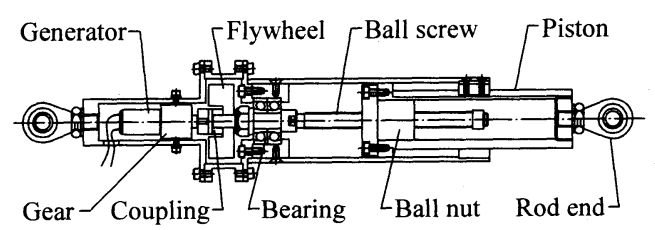

Fig. 1 Construction of the test V.C.D.

Table 1 Design parameters of the test V.C.D.

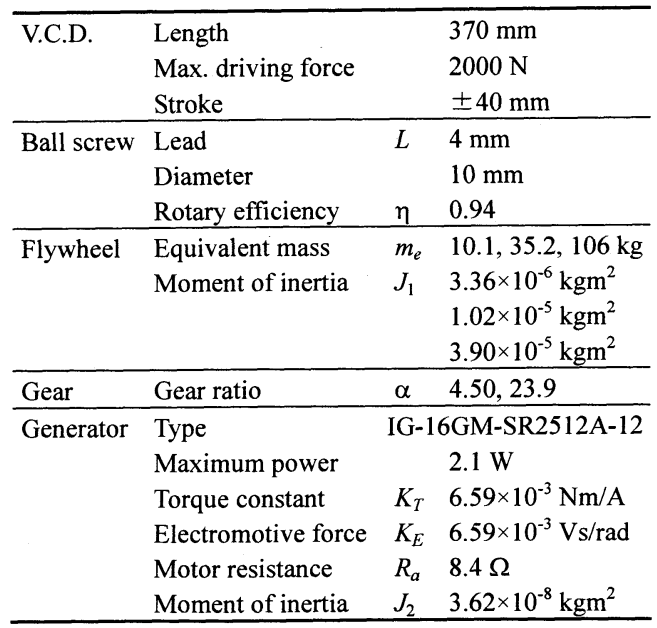




$$
F=\frac{1}{\eta}\left(\frac{2 \pi}{L}\right)^{2}\left(\left(J_{1}+\alpha^{2} J_{2}\right) \ddot{u}+\frac{K_{E} K_{r}}{R_{t}+R_{a}} \alpha^{2} \dot{u}\right)
$$

上式の加速度項の係数を等価慣性質量 $m_{e}$ として表す.

\section{3. 抵抗力測定実験}

$3 \cdot 1$ 実験装置 本装置を製作し, 図 2 に示すよう に装置の一端をロードセルを介して加振機に，他端を 固定板に取付けて, 正弦状変位を与えたときの力と変 位の関係を調べた．まず低周波数での減衰力を調べる ために，フライホイールを取外して，ギアの増速比を 23.9, 振幅 $20 \mathrm{~mm}$, 周波数を $0.04 \sim 0.3 \mathrm{~Hz}$ に変化させ て加振した. 次に, ギアの増速比を 4.5 , 振幅 $30 \mathrm{~mm}$, 周波数を $1.0 \mathrm{~Hz}$ でフライホイールを取付けて三種類の 慣性質量 $(10.1,35.2,106 \mathrm{~kg})$ に変化させて加振した. それぞれ，発電機の端子間を短絡および開放の二通り 行った．変位は差動型変位計を用いて $\mathrm{AD}$ 変換し，パ ーソナルコンピューターに取込んで測定した.

3・2 実験結果 図 $3(\mathrm{a})$ にフライホイールの無い 場合を，図 $3(\mathrm{~b})$ に取付けた場合をそれぞれ示す，実験 結果から，端子開放時のシリンダとピストン間に働く 摺動抵抗はおよそ $30 \mathrm{~N}$ であった。 これを考慮し，式(9) から得られる理論値と併せて示す．図 3 (a)より，低周 波数域においてもだ円形で示される速度比例型の減衰 力および摩擦力が組合わさった特性を示すことがわか る.また，図 $3(\mathrm{~b})$ より，等価慣性質量に比例して左肩 上がりの直線勾配が増し，慣性力の効果が現れている ことがわかる．実験值と理論値との誤差は，ギアの増 速比が増すにつれて軸端の回転数が上がるため減衰力 が増加し，それに伴いボールねじに作用する力も増大 するため逆変換効率が低下することによると考えられ る。また，ピストンとシリンダ間における摺動抵抗の 変化による影響も考えられるが，本実験ではわずかで あった。

\section{4. 周波数応答実験}

$4 \cdot 1$ 実験装置と解析モデル 本制振装置の振動 抑制効果を確かめるために，図 4 に示すような板ばね を用いた一自由度振動モデルに本制振装置を取付けて， 周波数応答実験ならびに解析を行った. 実験装置の諸 元を表 2 に示す. 主質量の絶対変位を $x$ とし, 基礎部 に入力変位 $z$ が作用したときの運動方程式は

$$
m \ddot{x}+c(\dot{x}-\dot{z})+k(x-z)+F=0
$$

となり, $F$ は式(9)から得られる抵抗力である. 相対変 位 $u(=x-z)$ として書き直すと $\left(m+m_{e}\right) \ddot{u}+\left(c+c_{d}\right) \dot{u}+k u=-m \ddot{z}$ ここで， $c_{d}$ はダンパが発生することができる減衰係数 である. 定常応答を $x=x_{0} e^{i \omega t}, z=z_{0} e^{i \omega t}$ とすると, 伝 達率 $T\left(=x_{0} / z_{0}\right)$ は次式となる ${ }^{(13)(14)}$.

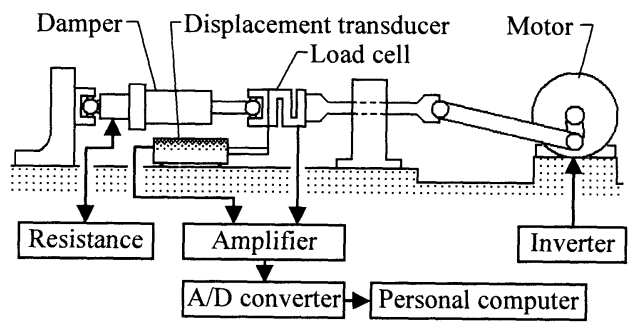

Fig. 2 Experimental apparatus
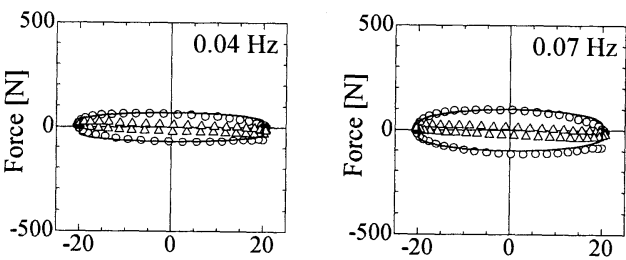

Displacement [mm]

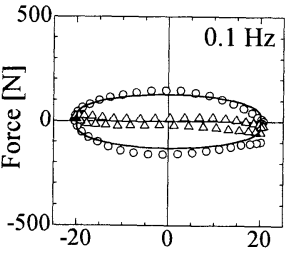

Displacement [mm]

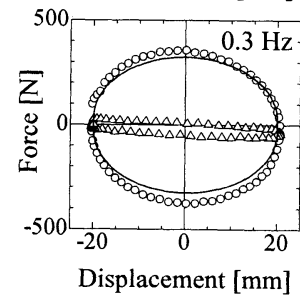

(a) Without the flywheel $\left(\alpha=23.9, m_{e}=0\right)$

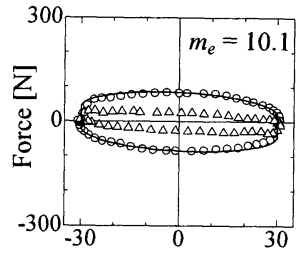

Displacement [mm]

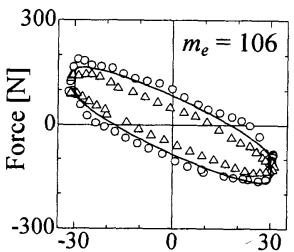

Displacement [mm]

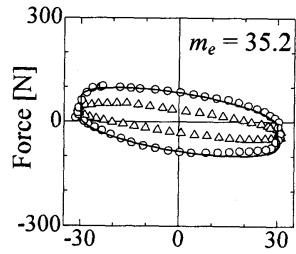

Displacement [mm]

Experiment

$\triangle$ Open circuit

O Closed circuit

Calculation

— Closed circuit (b) With the flywheel $(\alpha=4.5,1.0 \mathrm{~Hz})$

Fig. 3 Resisting force characteristics 


$$
T=\sqrt{\frac{\left(k-m_{e} \omega^{2}\right)^{2}+\left(c+c_{d}\right)^{2} \omega^{2}}{\left\{k-\left(m+m_{e}\right) \omega^{2}\right\}^{2}+\left(c+c_{d}\right)^{2} \omega^{2}}}
$$

上式を整理すると

$$
T=\sqrt{\frac{\left(1-\varepsilon \Omega^{2}\right)^{2}+(2 \zeta \Omega)^{2}}{\left\{1-(1+\varepsilon) \Omega^{2}\right\}^{2}+(2 \zeta \Omega)^{2}}}
$$

ここで,

$$
\Omega=\frac{\omega}{\omega_{n}}, \omega_{n}=\sqrt{\frac{k}{m}}, \varepsilon=\frac{m_{e}}{m}, \zeta=\frac{c+c_{d}}{2 \sqrt{m k}}
$$

内部減衰係数 $c$ は, 一次自由振動モードの対数減衰 率から求めた值である. 実験は, 質量比をを 0.3 に固定 し短絡および開放状態にした場合，および開放状態に 固定して三種類の質量比 $\varepsilon=0.3,1,3$ に変化させた場 合の二通りについて，それぞれ主質量および基礎部の 絶対変位を測定し, 振幅比を算出した。

$4 \cdot 2$ 実験結果 周波数応答の実験結果を計算結 果と併せて図 5 に示す. 図 $5(\mathrm{a})$ から, 最大振幅のピー ク値は制振装置が無い場合に比べて開放時で $1 / 5$ 程度 短絡時で $1 / 10$ 程度に低減していることがわかる. 端子 間を短絡にした場合，減衰効果が大きくなることが確 認された．図 5 (b)から，慣性質量が大きくなるにつれ て共振ピーク値が大幅に低減され，一次共振点が低振 動数側に移動することがわかる．また，計算結果がほ ぼ実験結果に一致していることから，解析の有効性が 確認された.

\section{5. 地震応答シミュレーション}

$5 \cdot 1$ 制御手法本制振装置の地震時に対する構 造物への振動抑制効果を確かめるために，周波数応答 実験で用いた一自由度振動モデルによる地震応答シミ ュレーションを行った．式(11)を状態空間方程式で表 すと

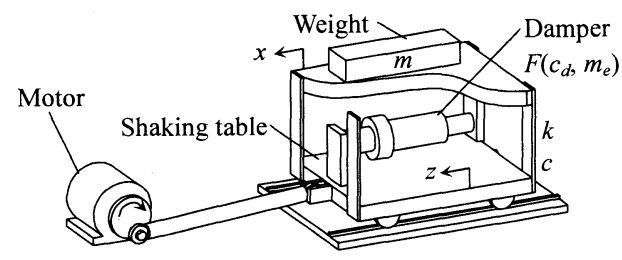

Fig. 4 Experimental setup of 1DOF system

Table 2 Design parameters of the 1DOF system

\begin{tabular}{lll}
\hline Primary mass & $m$ & $35.2 \mathrm{~kg}$ \\
Stiffness & $k$ & $7.42 \mathrm{kN} / \mathrm{m}$ \\
Internal damping & $c$ & $30.7 \mathrm{Ns} / \mathrm{m}$ \\
\hline
\end{tabular}

$$
\dot{U}=[A] U+[B] \Delta+[C] \ddot{z}
$$

ここで $\Delta$ は制御力, $A, B, C$ はそれぞれシステム行列, 入力行列, 外乱行列で以下のように表される.

$$
\begin{aligned}
& {[A]=\left[\begin{array}{cc}
0 & 1 \\
-k /\left(m+m_{e}\right) & -c /\left(m+m_{e}\right)
\end{array}\right]} \\
& {[B]=\left[\begin{array}{c}
0 \\
-1 /\left(m+m_{e}\right)
\end{array}\right], \quad[C]=\left[\begin{array}{c}
0 \\
-m /\left(m+m_{e}\right)
\end{array}\right]} \\
& U=\left[\begin{array}{ll}
u & \dot{u}
\end{array}\right]^{T}
\end{aligned}
$$

制御手法は，最適レギュレータを規範とするセミア クティブ制御を用い, 以下の評価関数 $J$ 設けた ${ }^{(18)(19)}$.

$$
\begin{aligned}
J & =\int_{0}^{\infty}\left(q_{1} u^{2}+q_{2} \dot{u}^{2}+q_{3} \Delta^{2}\right) d t \\
& =\int_{0}^{\infty}\left(U^{T} Q U+\Delta^{T} R \Delta\right) d t
\end{aligned}
$$

ここで $q_{1}, q_{2}, q_{3}$ はそれぞれ相対変位, 相対速度, 制 御入力に対する重み係数, および $Q, R$ は重み行列で,

$$
Q=\left[\begin{array}{cc}
q_{1} & 0 \\
0 & q_{2}
\end{array}\right], \quad R=q_{3}
$$

と表される.上式から最適な制御入力 $\Delta$ を求めると

$$
\Delta=-R^{-1} B^{T} P U
$$

ここで, $P$ は以下のリカッチ型代数方程式の正定対称 解である。

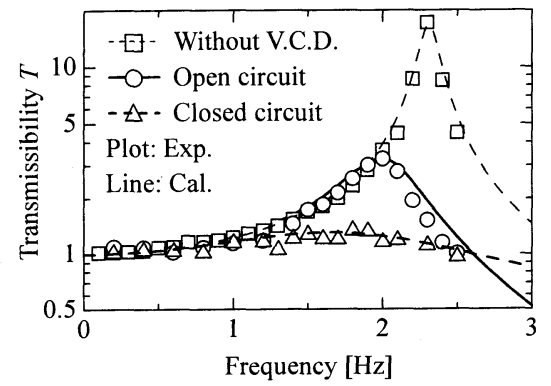

(a) Open and closed circuits with the fixed inertial mass $(\varepsilon=0.3)$

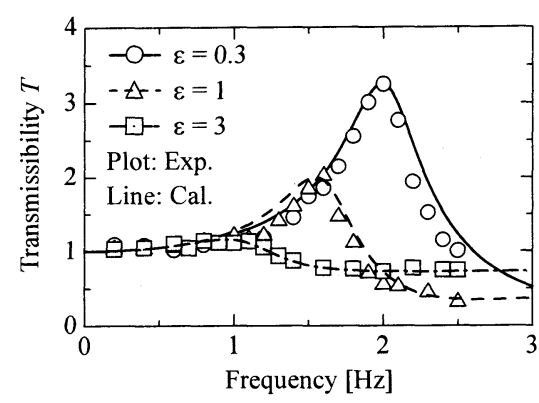

(b) Effect of the inertial mass variation on the transmissibility in the open circuit

Fig. 5 Frequency responses of the 1DOF system with the V.C.D. 


$$
P A+A^{T} P-P B R^{-1} B^{T} P+Q=0
$$

セミアクティブ制御則として,ダンパの減衰係数を, その発生力が制御力 $\Delta$ 可能な限り等しくなるように 変更する方法をとる ${ }^{(20)}$. 具体的には, 制御入力 $\Delta$ ダダ ンパの減衰係数の調整で実現できる（ $\Delta$ と $\dot{u}$ の符号が 等しい）場合は減衰係数をそのように変更し，それ以 外（ $\Delta$ と $\dot{u}$ の符号が異なる）の場合はダンパの減衰倸 数はそのノミナル値に保持する。この方針に基づき， ダンパの発生力 $F_{d}$ を, 次式のように与える.

$$
F_{d}= \begin{cases}\Delta & (\Delta \dot{u}>0) \\ 0 & (\Delta \dot{u} \leq 0)\end{cases}
$$

ただし, 装置が発生できる減衰係数には上限がある. その上限值を $c_{\max }$ とすると, $c>c_{\max }$ の場合は $c=c_{\max }$ とする. なお数值計算には MATLAB を用い, 減衰係 数の変更に伴い生じる時間遅れは考慮していない.

$5 \cdot 2$ シミュレーション結果＼cjkstart本報で用いた地震 波は最大加速度 $0.5 \mathrm{~m} / \mathrm{s}^{2}$ に基準化した Imperial Valley 地震（1940）El Centro NS 成分，および日本建築セン ター模擬波 $\mathrm{BCJ}-\mathrm{L} 1$ 波と $\mathrm{BCJ}-\mathrm{L} 2$ 波である.この波形を 基礎部に入力した場合の主質量における絶対加速度, および相対変位を計算した，応答波形の最大値を表 3 に, El Centro および BCJ-L1 の忘答波形をそれぞれ図 6,7 に示す.

表 3 より，非制御時では慣性質量を増加させること により絶対加速度および相対変位ともに低減されるが, $\varepsilon=3$ 程度になると, 大きな慣性質量によって, 少しの 変位でも高振動数であれば抵抗力が大きくなり，相対 運動が起こりにくくなるため, 剛体のように動作して しまい, 加速度が低減しない場合がある.制御時では, 非制御時より絶対加速度および相対変位の低減が図ら れている。また，慣性質量の影響で，構造物の共振周 波数域を変更できるので, 地震波の卓越周波数近傍に させないように慣性質量を調整することで，構造物の 振動を大幅に低減させることが可能となる.

$$
\text { 6. ま と め }
$$

本研究では, 発電機式振動抑制装置を設計製作し, その抵抗力特性を実験と解析により確かめた。また, 周波数応答実験を行い, その振動抑制効果を検証した. 主な結果は以下のとおりである。

（1）発電式振動抑制装置の抵抗力は，低振動数域に おいても, 速度比例型の減衰力と慣性力が足し合わさ つた特性をもつ。

（2）ギアの増速比が低い場合は実験值と理論值はほ ぼ一致する．増速比の高い場合の理論値と実験値の間 の誤差は, 増速比の増加に伴いボールねじの逆変換効 率の低下によるものと思われる.

（3）振動抑制装置の発電機両端子間を短絡にすると 減衰力は最大に，また開放にすると減衰力はほぼ零に なる。

（4）一次元振動モデルの周波数応答実験の結果，振 動抑制装置の慣性質量によって共振点におけるピーク 值が低减し, それに伴い共振周波数が低下する.また, 実験結果と計算結果がほぼ一致していることから，理 論の正当性が確認された.

（5）地震応答シミュレーションの結果, 最適レギュ レータを用いた制御時における絶対加速度および相対 変位は, 非制御時より小さくなり, その制振効果は高 いことがわかる，また，慣性質量を調整することによ り, 構造物の振動を低減させることが可能である.

最後に, 本研究を遂行するにあたり実験施設等のご 協力を頂いた三和テッキ（株）に謝意を表する.

\section{文献}

(1) Shibata, H., Seismic Design for Chemical Plants (in Japanese), (1986) p. 278-282, Maruzen.

(2) Yamamoto, S., et al., An Eathquake Isolating an Vibration Absorbing Equipment for Spherical Tanks, J. High Pressure Institute of Japan, Vol. 13, No. 5 (1975), pp. 235-243.

(3) Kawamata, S., et al., Development of Aseismic Damping Mechanism for Structures, Seisan Kenkyu, Institute of Industrial Science, The University of Tokyo, Vol. 25, No. 3 (1973), pp. 130-135.

(4) Kawaguchi, O., et al., Research and Development of Seismic Restraint Snubbers (I), J. At. Energy Soc. Japan, Vol. 33, No. 1 (1991), pp. 76-89.

(5) Sunakoda, K., et al., Study of a High Damping Device based on Electricity Generating System, ASME, Proc. PVP1992, No. 229 (1992), pp. 133-136.

Table 3 Maximum values of seismic responses

\begin{tabular}{|l|l||c|c||c|c||c|c|}
\hline \multicolumn{2}{|c||}{ Input acceleration wave } & \multicolumn{2}{c||}{ El Centro NS $0.5 \mathrm{~m} / \mathrm{s}^{2}$} & \multicolumn{2}{c|}{ BCJ-L1 $0.5 \mathrm{~m} / \mathrm{s}^{2}$} & \multicolumn{2}{c|}{ BCJ-L2 0.5 m/ $\mathrm{s}^{2}$} \\
\hline \multicolumn{2}{|l||}{} & $\begin{array}{c}\text { Accel. } \\
\ddot{x}\left[\mathrm{~m} / \mathrm{s}^{2}\right]\end{array}$ & $\begin{array}{c}\text { Disp. } \\
u[\mathrm{~mm}]\end{array}$ & $\begin{array}{c}\text { Accel. } \\
\ddot{x}\left[\mathrm{~m} / \mathrm{s}^{2}\right]\end{array}$ & $\begin{array}{c}\text { Disp. } \\
u[\mathrm{~mm}]\end{array}$ & $\begin{array}{c}\text { Accel. } \\
\ddot{x}\left[\mathrm{~m} / \mathrm{s}^{2}\right]\end{array}$ & $\begin{array}{c}\text { Disp. } \\
u[\mathrm{~mm}]\end{array}$ \\
\hline \multirow{4}{*}{ Without V.C.D. } & 0.767 & 3.58 & 1.943 & 9.18 & 1.671 & 7.89 \\
\hline \multirow{3}{*}{ With V.C.D. } & LQR control $\varepsilon=0.3$ & 0.440 & 2.23 & 0.643 & 2.95 & 0.662 & 3.07 \\
\cline { 2 - 9 } & Passive $\varepsilon=0.3$ & 0.435 & 2.26 & 0.644 & 2.94 & 0.664 & 3.07 \\
\cline { 2 - 9 } & Passive $\varepsilon=1$ & 0.268 & 2.08 & 0.579 & 3.24 & 0.604 & 3.46 \\
\cline { 2 - 9 } & Passive $\varepsilon=3$ & 0.330 & 1.30 & 0.437 & 2.70 & 0.449 & 3.01 \\
\hline
\end{tabular}




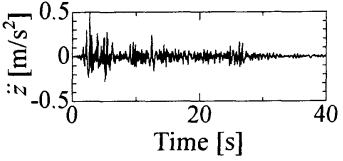

(a) Input acceleration
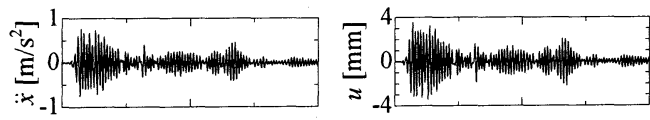

(b) Without V.C.D.
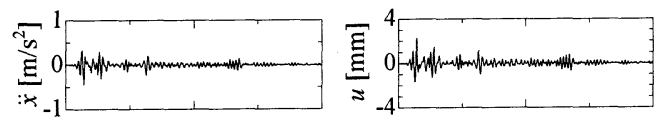

(c) LQR control
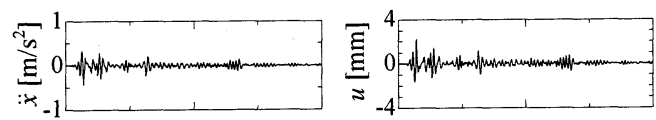

(d) Passive $\varepsilon=0.3$
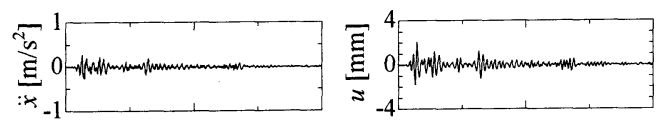

(e) Passive $\varepsilon=1$
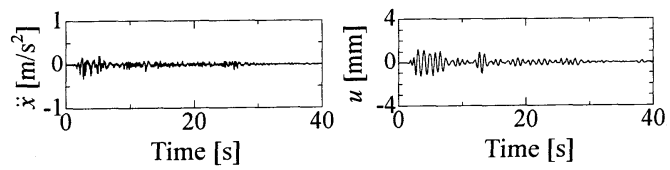

(f) Passive $\varepsilon=3$

Fig. 6 Seismic response wave (El Centro NS)

(6) Iwata, Y., et al., Semiactive Control of Seismic Isolation System using Mechatro Damper, ASME, Proc. PVP1994, Vol. 275-2 (1994), pp. 129-135.

(7) Sunakoda, K., et al., Semiactive Control of Seismic Isolation System Using Mechatro Damper, Transactions of the Japan Society of Mechanical Engineers, Series C, Vol. 61, No. 584 (1995), pp. 1308-1312.

(8) Iwata, Y., et al., Hybrid Control of Seismic Isolation System using Mechatro Damper, Transactions of the Japan Society of Mechanical Engineers, Series C, Vol. 63, No. 613 (1997), pp. 2991-2995.

(9) Ohmata, K., Resisting Force Characteristics of a Mechanical Snubber and Its Restraint Effect on Beam Deformation, Transactions of the Japan Society of Mechanical Engineers, Series C, Vol. 53, No. 492 (1987), pp. 1697-1703.

(10) Ohmata, K., et al., A Seismic Isolator Using the Ball Screw-Type Damper with Magnetic Damping, Transactions of the Japan Society of Mechanical Engineers, Series C, Vol. 57, No. 535 (1991), pp. 734-739.

(11) Furuhashi, T. and Ishimaru, S., Mode Isolation by Inertia Mass: Study on Response Control by Inertia Mass No.1, $J$. Struct. Constr. Eng., AIJ, No. 576 (2004), pp. 55-62.

(12) Kawamata, S. and Onuma, M., Control of Structural Vibration by Inertia Pump Damper: Part I Theoretical Model and Response to Harmonic Excitation, Summaries of Technical Papers of Annual Meeting Architectural Institute of Japan (1986), pp. 771-772.

(13) Sunakoda, K. and Matsuoka, T., Vibration Tests of a Cut-off System Using Water and Functional Fluids, ASME Proc. PVP2006-ICPVT-11, No. 93532 CD-ROM (2006-7), 4p.

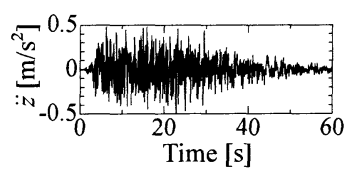

(a) Input acceleration
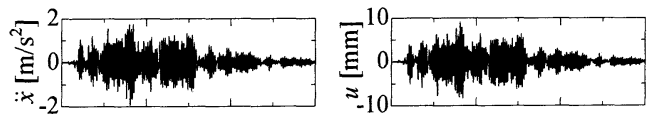

(b) Without V.C.D.

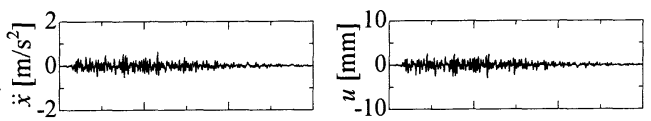

(c) LQR control
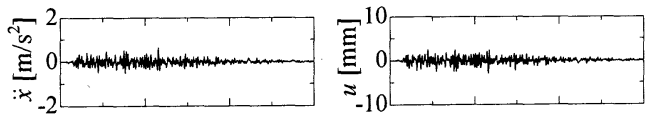

(d) Passive $\varepsilon=0.3$
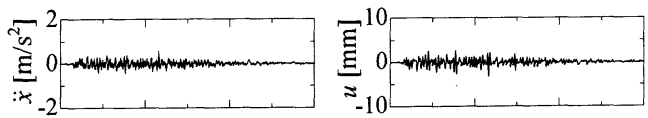

(e) Passive $\varepsilon=1$
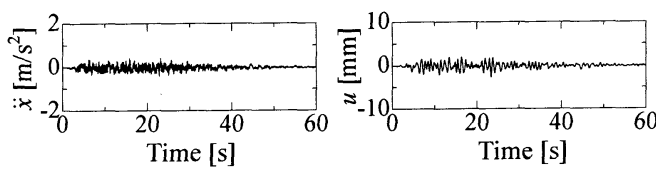

(f) Passive $\varepsilon=3$

Fig. 7 Seismic response wave (BCJ-L1)

(14) Sunakoda, K., et al., Study on a Cut-off System for Vibration Control using Water and Functional Fluids, JSME Dynamics and Design Conference 2005, No. 319 CD-ROM (2005-8), $4 \mathrm{p}$.

(15) Ohtake, T., et al., Study on Vibration Control Device Using Power Generator, ASME Proc. PVP2006-ICPVT-11, No. 93534 CD-ROM (2006-7), 5p.

(16) Sunakoda, K., et al., Study on a Vibration Control Device Using Power Generator, JSME Dynamics and Design Conference 2005, No. 307 CD-ROM (2005-8), 5p.

(17) Matsuoka, T., et al., Numerical Simulations of 3-Story Structure with Vibration Control Device, Proc. 4th International Conference on Earthquake Engineering, No. 199 CD-ROM (2006-10), 8p.

(18) Hiwatashi $T$, et al., Semi-Active Base-Isolation System by MR Damper Utilizing Optimal Regulator Theory, J. Struct. Constr. Eng., AIJ, No. 567 (2003), pp. 47-54.

(19) Sato, E. and Fujita, T., Semi-Active Seismic Isolation System with Controllable Viscous Dampers Using MagnetoRheological Fluid, Transactions of the Japan Society of Mechanical Engineers, Series C, Vol. 72, No. 717 (2006), pp. 1428-1434

(20) Karnopp, D., et al., Vibration Control Using Semi-active Force Generator, Transactions of the ASME, Journal of Engineering for Industry, Vol. 96 (1974), pp. 619-626. 